\title{
Changes of Cortical Perfusion in the Early Phase of Subarachnoid Bleeding in a Rat Model and the Role of Intracranial Hypertension
}

\author{
M. KOLAR ${ }^{1}$, K. NOHEJLOVA ${ }^{2}$, F. DUSKA ${ }^{1}$, J. MARES $^{2}$, J. PACHL $^{1}$ \\ ${ }^{1}$ Department of Anaesthesiology and Intensive Care Medicine, Teaching Hospital Kralovske \\ Vinohrady and Third Faculty of Medicine, Charles University, Prague, Czech Republic, \\ ${ }^{2}$ Department of Normal, Pathological and Clinical Physiology, Third Faculty of Medicine, Charles \\ University, Prague, Czech Republic
}

Received March 24, 2017

Accepted September 6, 2017

\begin{abstract}
Summary
Brain perfusion is reduced early after subarachnoid hemorrhage (SAH) due to intracranial hypertension and early vasospasm. The contribution of these two mechanisms is unknown. By performing a prophylactic decompressive craniectomy (DC) in a rat model of SAH we aimed to study brain perfusion after the component of intracranial hypertension has been eliminated. We used $2 \times 2$ factorial design, where rats received either decompressive craniectomy or sham operation followed by injection of $250 \mu \mathrm{l}$ of blood or normal saline into prechiasmatic cistern. The cortical perfusion has been continually measured by laser speckle-contrast analysis for $30 \mathrm{~min}$. Injection of blood caused a sudden increase of intracranial pressure (ICP) and drop of cerebral perfusion, which returned to baseline within $6 \mathrm{~min}$. DC effectively prevented the rise of ICP, but brain perfusion after $\mathrm{SAH}$ was significantly lower and took longer to normalize compared to non-DC animals due to increased cerebral vascular resistance, which lasted throughout 30 min experimental period. Our findings suggest that intracranial hypertension plays dominant role in the very early hypoperfusion after SAH whilst the role of early vasospasm is only minor. Prophylactic DC effectively maintained cerebral perfusion pressure, but worsened cerebral perfusion by increased vascular resistance.
\end{abstract}

\section{Key words}

Subarachnoid hemorrhage • Decompressive craniectomy • Early brain injury • Laser speckle-contrast analysis • Rat

\section{Corresponding author}

M. Kolar, Department of Anesthesiology and Critical Care
Medicine, Teaching Hospital Kralovske Vinohrady and Third Faculty of Medicine, Charles University, Srobarova 50, 10034 Prague, Czech Republic. Fax: +420 2671631 25. E-mail: martin.kolar.78@gmail.com

\section{Introduction}

Aneurysmal subarachnoid hemorrhage (SAH) is a cerebrovascular accident with high mortality, which causes both early and delayed changes of brain perfusion. Development of early brain injury (EBI) after subarachnoid aneurysm rupture has a complex pathogenesis (Sehba et al. 2012). Vascular wall rupture leads to immediate inflow of arterial blood into subarachnoid space under pressure equal to arterial blood pressure. This causes a rapid increase of intracranial pressure (ICP), which in turn reduces cerebral perfusion pressure (CPP) and cerebral blood flow (CBF), resulting in EBI (Bederson et al. 1995, Prunell et al. 2003, Prunell et al. 2004). In addition, early vasoconstriction of both large and small cerebral parenchymal vessels, which occurs within minutes after hemorrhage, further reduces CBF (Bederson et al. 1998, Sehba et al. 2012). The proportion of these two mechanisms on the development of EBI remains uncertain. In order to elucidate the relative contribution of raised ICP and early vasospasms on EBI, we measured changes of CBF after $\mathrm{SAH}$ in rats with and without decompressive craniectomies performed before the induction of SAH. We hypothesized that elimination of intracranial hypertension achieved by 
decompressive craniectomy (DC) can improve the early hypoperfusion.

\section{Methods}

All procedures were performed in accordance with the Guidelines of the Animal Protection Law of the Czech Republic, which comply with the respective EU regulations. Special care was taken to minimize animal suffering.

Young adult male Wistar rats (AnLab, Czech Republic; 220-240 g) were used. The animals were housed in cages by four under a 12-hour light/dark cycle, with free access to food and water.

Surgical preparation of animals and induction of nontraumatic $S A H$

Thirty six animals were divided into four groups. There were two experimental groups: 1. animals with induced non-traumatic subarachnoid hemorrhage ( $\mathrm{SAH}$, $\mathrm{n}=12$ ); 2. animals with decompressive craniectomy and SAH (DC-SAH, $\mathrm{n}=8$ ); and two control groups: 3. sham-operated animals that receive normal saline solution of body temperature into the subarrachnoidal space instead of blood (Sham, $n=8$ ); and 4. shamoperated animals with decompressive craniectomy and normal saline injection (DC-Sham, $\mathrm{n}=8$ ).

All procedures were conducted under deep general anaesthesia (ketamine $100 \mathrm{mg} / \mathrm{kg}$ and midazolam $1.2 \mathrm{mg} / \mathrm{kg}$, i.p.) with additional local anaesthesia of the skin and subcutaneous tissues of the head (trimecaine $1 \%$ $0.3 \mathrm{ml})$.

The skull of the animals was exposed from soft tissues. In DC groups (DC-SAH and DC-Sham), bilateral fronto-temporo-parietal craniectomy and durotomy were performed. The craniectomy extended to the lambdoid suture caudally and $2 \mathrm{~mm}$ ahead from the coronal suture rostrally. The medial border was the sagittal suture; the lateral border approached the floor of the middle fossa. The dura was opened by a large cruciate incision. In non-DC groups (SAH and Sham), the skull above right hemisphere was mechanically thinned to allow the measurement of brain perfusion.

Femoral artery was cannulated for blood pressure measurement and also for obtaining blood to be used for $\mathrm{SAH}$ induction.

An ICP probe (Codman Microsensor ICP transducer, Johnson \& Johnson Health Care Systems,
USA) was inserted into left cerebellar hemisphere as previously described (Rooker et al. 2002) in order to avoid changes of $\mathrm{CBF}$ caused by supratentorial ICP monitoring (Verhaegen et al. 1992). ICP and arterial blood pressure were measured continuously (ICP Express, Johnson \& Johnson Health Care Systems, USA) during the whole 30-minute monitored period. CPP was calculated as MAP - ICP.

The prechiasmatic cistern injection model of subarachnoid hemorrhage was induced as previously described (Prunell et al. 2002). Briefly, a small borehole was drilled $7 \mathrm{~mm}$ rostrally from the bregma. A needle with $26 \mathrm{G}$ cannula was inserted into the prechiasmatic cistern at the $30^{\circ}$ angle anteriorly. The cannula was fixed to the skull and the needle was removed. In the $\mathrm{SAH}$ groups (SAH and DC-SAH), $250 \mu \mathrm{l}$ of fresh non-heparinized autologous arterial blood was injected during $15 \mathrm{~s}$, whilst sham animals (Sham and DC-Sham) received $250 \mu \mathrm{l}$ of normal saline solution of body temperature. The amount of both blood and normal saline solution was derived from previous studies (Prunell et al. 2003) as well as previous experiments in our laboratory which showed significant hypoperfusion with acceptable mortality rate (approx. $25 \%$ ).

Rectal temperature was monitored and maintained at $37{ }^{\circ} \mathrm{C}$ throughout the experiment.

\section{Measurement of cerebral perfusion}

Changes in the perfusion of cerebral cortex were assessed using Laser speckle-contrast analysis (LASCA). This method is based on the detection of moving particles; in case of tissue perfusion these are erythrocytes (Dunn et al. 2001). High resolution apparatus PeriCam PSI HR using PimSoft software (Perimed, Sweden) was used for measurement. The cerebral perfusion was measured in arbitrary perfusion units (PU) and reported as percent of deviation from the baseline (i.e. perfusion during $1 \mathrm{~min}$ before induction of $\mathrm{SAH}$ ). The device allows to measure cerebral perfusion in designated regions of interest (ROIs). In non-DC animals, the ROI was placed over the right hemisphere where skull was thinned; in DC animals, the perfusion was measured over the craniectomies.

\section{Statistical analysis}

Cerebral perfusion pressure was determined as MAP-ICP. As a measure of the degree of vasoconstriction, we calculated resistance of cerebral 
vascular bed as CPP divided by a change of perfusion

$$
\mathrm{R}=\mathrm{CPP} / \Delta \text { perfusion, }
$$

calculated as the percentage of the baseline values. GraphPad Prism 6 (GraphPad Software, Inc., USA) was used for statistical evaluation. Changes in ICP, CPP, perfusion and cerebral vascular resistance between groups were compared using two-way ANOVA for repeated measures with Bonferroni's post hoc test. Data are shown as mean \pm SEM. Differences were considered significant at $\mathrm{p}<0.05$.

\section{Results}

Determinants of cerebral perfusion. Immediate effects of subarachnoidal injection

DC ameliorated the early rise of ICP after subarachnoidal injection of both blood $(74.8 \pm 11.5$ vs. $18.4 \pm 4.6 \mathrm{~mm} \mathrm{Hg}, \mathrm{p}<0.001)$ and normal saline $(76.2 \pm 6.9$ vs. $20.7 \pm 1.7 \mathrm{~mm} \mathrm{Hg}, \mathrm{p}<0.001$; Fig. 1A), and because there were no significant differences among groups in the dynamics of MAP, CPP followed the trends observed for ICP (Fig. 1B). In all groups ICP and CPP returned to physiologic levels within 4 min. (Fig. 1A, B).

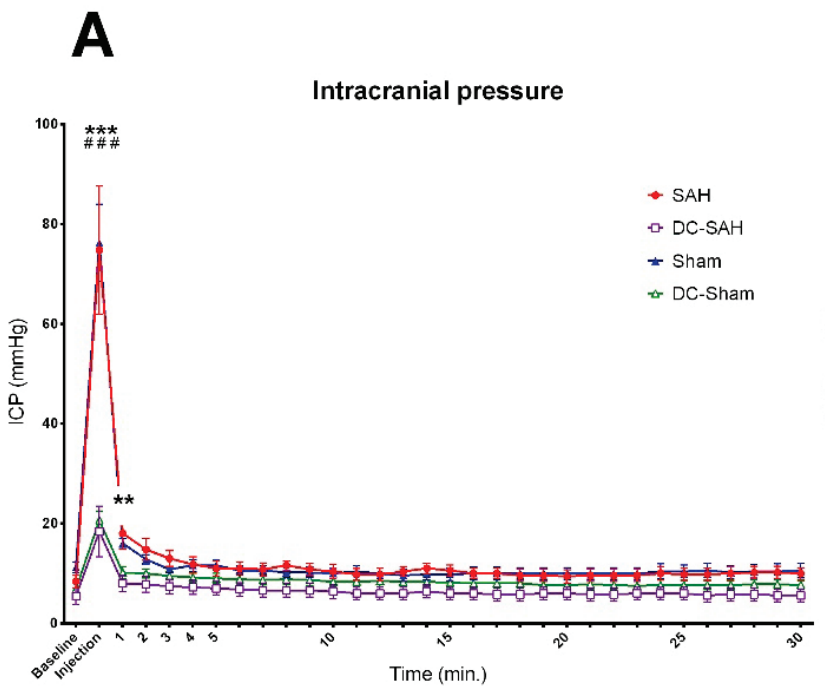

B
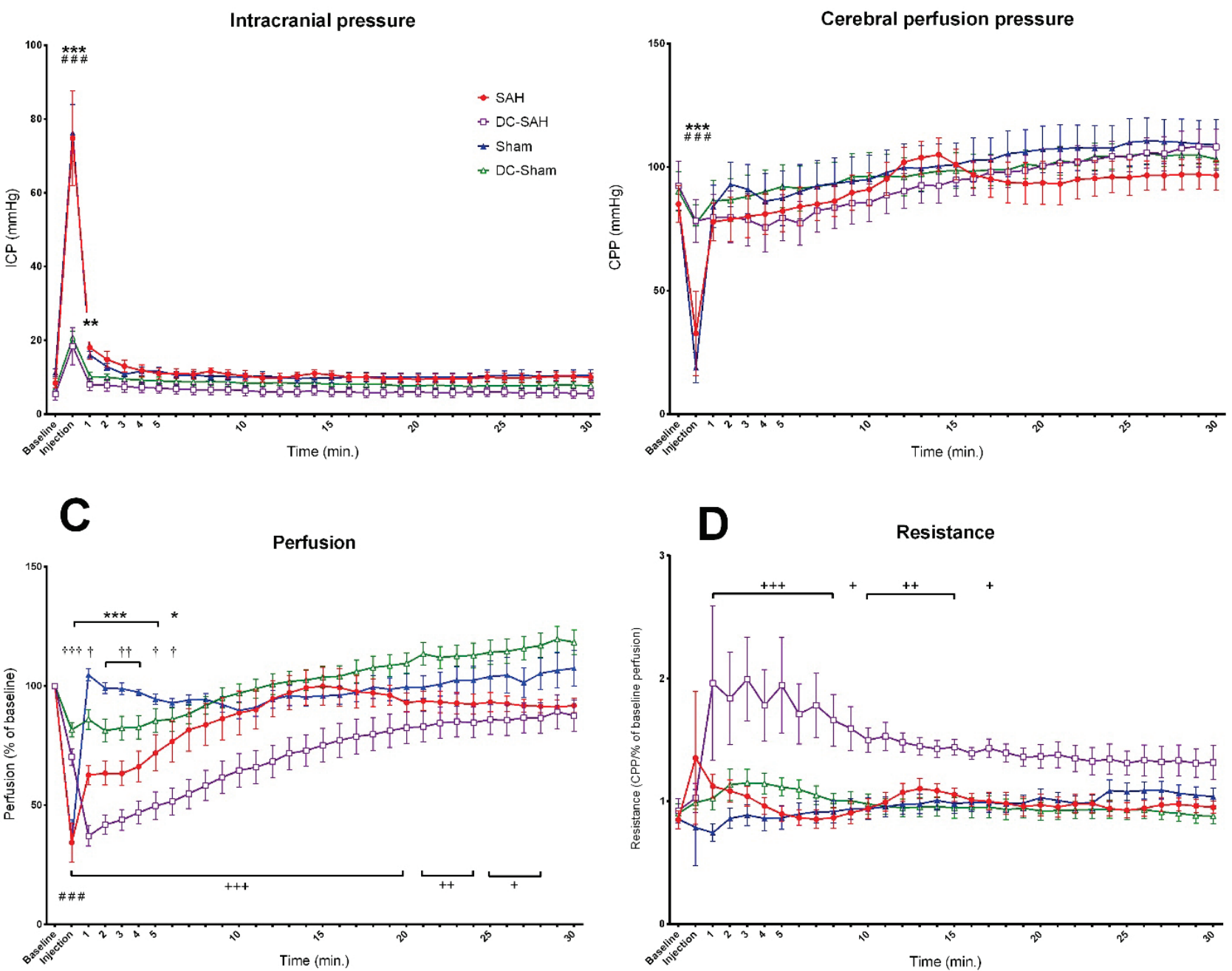

Fig. 1. (A) Preemptive decompressive craniectomy significantly reduced ICP after injection in both DC-SAH $(* * p<0.01, * * * p<0.001)$ and DC-Sham groups (\#\# ${ }^{\#<0.001)}$, compared to the respective non-DC groups. (B) The rise of ICP was accompanied by the drop of CPP in both SAH and Sham groups $(* * *, \# \# p<0.001)$. (C) Compared to baseline, brain perfusion was significantly reduced in all groups at the time of subarachnoid injection $(p<0.001$ for all groups). SAH animals showed significantly reduced perfusion within first $6 \mathrm{~min}(* p<0.05, * * * p<0.001)$, whilst in DC-SAH group the perfusion was reduced till $28^{\text {th }}$ minute $\left({ }^{+} p<0.05,{ }^{++} p<0.01,{ }^{+++} p<0.001\right)$. Hypoperfusion was observed even in DC-Sham group $\left({ }^{+} p<0.05,{ }^{++} p<0.01\right)$. (D) The increase of resistance was observed only in DC-SAH group and it persisted till $16^{\text {th }}$ minute after SAH induction $\left({ }^{+} p<0.05,{ }^{++} p<0.01,{ }^{+++} p<0.001\right)$. Data are shown as mean \pm SEM. 
Increased ICP at the time of intracisternal injection caused a severe reduction of perfusion in both $\mathrm{SAH}$ and Sham groups $(25.7 \pm 5 \%$ of baseline, $\mathrm{p}<0.001$, and $35.1 \pm 8.3 \%, \quad \mathrm{p}<0.001, \quad$ respectively). Reduced perfusion at the time of the injection was observed also in both DC-SAH and DC-Sham groups $(70.2 \pm 3.9 \%$ of baseline, $\mathrm{p}<0.001$, and $80.9 \pm 3 \%, \mathrm{p}<0.001$, respectively), nevertheless the hypoperfusion was less severe in comparison with respective non-DC groups $(p<0.001)$. In Sham group, the cerebral perfusion returned back to baseline within $1 \mathrm{~min}$ whilst it remained significantly reduced up to minute 6 after injection in SAH group ( $p<0.05$, compared to baseline; Fig. 1C). Surprisingly, in DC-SAH group, cerebral perfusion remained impaired up until minute $28(\mathrm{p}<0.05$, compared to baseline $)$, which was caused by increased resistance (Fig. 1C, D). Mild but significant $(p<0.05)$ hypoperfusion lasting for 6 min after the injection was observed even in DC-Sham animals (Fig. 1C).

\section{Changes of cerebral vascular resistance and the effect of} $D C$

Resistance of vascular bed did not change neither in SAH, Sham or DC-Sham group, whilst increased in DC-SAH group shortly after injection (at $20 \mathrm{~s}$ ) and remained above baseline level till minute 16 (Fig. 1D).

\section{Mortality}

Four animals $(25 \%)$ in the SAH group died within 2 min since the intracisternal injection. All animals in SAH-DC and both sham groups survived till the end of experiment.

\section{Discussion}

Perfusion of the brain (i.e. volume/time) is determined by cerebral perfusion pressure (i.e. MAP-ICP) and the global resistance of cerebral vessels to flow (calculated in Ohm's law analogy as CPP/flow). In the early phase after subarachnoidal hemorrhage, both determinants of cerebral perfusion change dynamically and contribute to impaired cerebral perfusion. The initial reduction of perfusion is attributed to increased volume of subarachnoid space and thus elevated ICP and decreased CPP (Bederson et al. 1995, Prunell et al. 2003, Sehba et al. 2012). Nevertheless, animal studies show that the perfusion remains reduced after CPP increase (Bederson et al. 1995, Prunell et al. 2003, Prunell et al.
2004, Schubert et al. 2008) and the hypoperfusion is not even related to development of brain edema and amount of brain water content (Westermaier et al. 2012). In the clinical setting, a significant reduction of $\mathrm{CBF}$ was observed within the first $12 \mathrm{~h}$ after aneurysm rupture, which correlated with Hunt-Hess grade, but not with ICP or CPP (Schubert et al. 2009). This hypoperfusion can be attributed to early vasoconstriction (and thus increased resistance to the blood flow) caused by nitric oxide (NO) scavenging and an impairment of endothelium - dependent vasodilation (Sehba et al. 2005). In this study we aimed to experimentally separate the impairment of CPP from changes of cerebral vascular resistance and analyze their respective contribution to the perfusion abnormalities.

The main finding of our study is that although preemptive DC prevented $25 \%$ of deaths after injecting blood into the subarachnoid space, it led to a protracted impairment of cerebral perfusion, which was mainly caused by increase resistance of cerebral vessels. The reasons why DC performed before SAH increased cerebral vascular resistance remain unclear. Reduced brain perfusion with DC preceding SAH has been seen before in a study (Buhler et al. 2015), where SAH was induced by endovascular puncture model (EPM). Because the intracranial hypertension contributes to the cessation of bleeding after aneurysm rupture (Nornes 1973), the DC before SAH could have led to a larger volume of the hematoma in EPM and thus made these results difficult to interpret. We avoided this bias by choosing to induce SAH by injection of a controlled volume of blood. Nonetheless, the volume was chosen as per described protocol (Prunell et al. 2002) and the results might have been different with different volumes of blood used (Bederson et al. 1998).

In our study, both groups with DC showed brain edema with protrusion of brain tissue after subarachnoid injection. Decreased perfusion in DC-SAH group could be explained by brain herniation, which is a frequent complication of decompressive craniectomy in humans (Yang et al. 2008). The protrusion of edematous brain tissue above the skull surface may lead to compression of vessels at the edge of the craniectomy and subsequent venous congestion and arterial occlusion (Huang and Wen 2010, Mitchell et al. 2004), together with a degree of an impairment of cerebral microvascular regulation and metabolic deterioration (Bor-Seng-Shu et al. 2013). The herniation was observed mostly in inappropriately small craniectomies and performing large fronto- 
temporo-parietal craniectomy appeared to prevent this complication (Forsting et al. 1995, Yang et al. 2008) and this is the surgical approach we used in our experiment. Nevertheless, the increased resistance of cerebral vessels together with mild reduction of perfusion in DC-Sham group suggests that DC itself could have increased cerebral vascular resistance to some extent. The expansion of edematous brain and the presence of blood cells in subarachnoid space in DC-SAH group could have exacerbated these mechanisms, together with causing axonal stretch and subsequent neuronal injury (Cooper et al. 2011).

Our experimental design was effective in terms of DC disturbing Monro-Kellie doctrine. In animals without DC, inducing a SAH caused a sharp rise in ICP, which resulted in a drop of CPP with a nadir close to 0 . This was the main factor impairing cerebral perfusion during this short period after injection, 4 out of 12 animals $(25 \%)$ died at this stage. DC allowed the intracranial volume to expand enough so that there was only a minor raise in ICP following induction of SAH. All animals with DC survived SAH. The reductions of $\mathrm{CBF}$ in both SAH and DC-SAH groups in our experiments were less marked compared to previous studies (Bederson et al. 1995, Prunell et al. 2003, Prunell et al. 2004, Schubert et al. 2008). This can be explained by both technique of SAH induction (Prunell et al. 2003) and the method of measurement of CBF. Especially in endovascular puncture model (EPM) of SAH, the presence of blood above brain convexities can induce bias into the perfusion measurement (Prunell et al. 2003). Also this model produces heterogeneity in the volume of blood in subarachnoid space, risks rebleeding and may induce vasospasms by a direct injury to vessel wall (Buhler et al. 2015, Prunell et al. 2003). Our model avoided all these disadvantages. On the other hand, LASCA method of brain perfusion measurement integrates the signal from both microcirculation and large pial vessels. In previous studies (Bederson et al. 1995, Prunell et al. 2003, Schubert et al. 2008) the CBF was measured by laser-Doppler flowmetry probes, which allow measurement in only approx. $1 \mathrm{~mm}^{3}$ of tissue (Dirnagl et al. 1989) and the probes were placed away from large pial vessels, which may increase the sensitivity to detecting perfusion changes at the level of microcirculation, which are indeed functionally more important (Herz et al. 1975, Park et al. 2001, Schubert et al. 2009).

Although putting our data into clinical context should be performed with caution, there are some interesting analogies. In SAH patients, the indication, timing and extent of DC have not been fully established yet (Buschmann et al. 2007, Otani et al. 2008). Even though prompt decrease of ICP and increase of partial pressure of $\mathrm{O}_{2}$ in brain tissue was described (Jaeger et al. 2003), the correlation with patient's outcome is rather weak (Uozumi et al. 2014). DC can be beneficial in some subgroups of patients, e.g. SAH with intracerebral hemorrhage or large Sylvian hematoma and our model did not involve these subgroups. The expansion of edematous brain can also cause axonal stretch and subsequent neuronal injury (Cooper et al. 2011). In our animal model, DC decreased mortality of SAH from $25 \%$ to $0 \%$, but worsened brain perfusion. In line, in high quality randomized controlled trial DC reduced mortality but increased proportion of severely disabled patients in brain trauma (Hutchinson et al. 2016) and similar results were observed in patients $\mathrm{SAH}$ (D'Ambrosio et al. 2005).

In conclusion, cerebral perfusion imminently after SAH was mainly impaired by increased intracranial pressure in this study. Then ICP, CPP and cerebral perfusion normalize within $6 \mathrm{~min}$. Pre-emptive DC effectively prevented the early alteration of cerebral perfusion pressure, but led to a protracted impairment of cerebral perfusion, almost solely attributed to increased cerebral vascular resistance. This phenomenon is likely caused by deleterious interaction between effects of DC itself and the blood in the subarrachnoidal space.

\section{Conflict of Interest}

There is no conflict of interest.

\section{Acknowledgements}

This study was supported by the project Progres Q35, Q37 and 260388/SVV/2017 from Charles University and from Institutional Support Program of Kralovske Vinohrady University Hospital in Prague.

\section{References}

BEDERSON JB, GERMANO IM, GUARINO L: Cortical blood flow and cerebral perfusion pressure in a new noncraniotomy model of subarachnoid hemorrhage in the rat. Stroke 26: 1086-1091; discussion 1091-1092, 1995. 
BEDERSON JB, LEVY AL, DING WH, KAHN R, DIPERNA CA, JENKINS AL 3RD, VALLABHAJOSYULA P: Acute vasoconstriction after subarachnoid hemorrhage. Neurosurgery 42: 352-360; discussion 360-362, 1998.

BOR-SENG-SHU E, FIGUEIREDO EG, FONOFF ET, FUJIMOTO Y, PANERAI RB, TEIXEIRA MJ: Decompressive craniectomy and head injury: brain morphometry, ICP, cerebral hemodynamics, cerebral microvascular reactivity, and neurochemistry. Neurosurg Rev 36: 361-370, 2013.

BUHLER D, AZGHANDI S, SCHULLER K, PLESNILA N: Effect of decompressive craniectomy on outcome following subarachnoid hemorrhage in mice. Stroke 46: 819-826, 2015.

BUSCHMANN U, YONEKAWA Y, FORTUNATI M, CESNULIS E, KELLER E: Decompressive hemicraniectomy in patients with subarachnoid hemorrhage and intractable intracranial hypertension. Acta Neurochir (Wien) 149: 59-65, 2007.

COOPER DJ, ROSENFELD JV, MURRAY L, ARABI YM, DAVIES AR, D'URSO P, KOSSMANN T, PONSFORD J, SEPPELT I, REILLY P, WOLFE R: Decompressive craniectomy in diffuse traumatic brain injury. $N$ Engl J Med 364: 1493-1502, 2011.

D'AMBROSIO AL, SUGHRUE ME, YORGASON JG, MOCCO JD, KREITER KT, MAYER SA, MCKHANN GM 2ND, CONNOLLY ES JR: Decompressive hemicraniectomy for poor-grade aneurysmal subarachnoid hemorrhage patients with associated intracerebral hemorrhage: clinical outcome and quality of life assessment. Neurosurgery 56: 12-19; discussion 19-20, 2005.

DIRNAGL U, KAPLAN B, JACEWICZ M, PULSINELLI W: Continuous measurement of cerebral cortical blood flow by laser-Doppler flowmetry in a rat stroke model. J Cereb Blood Flow Metab 9: 589-596, 1989.

DUNN AK, BOLAY H, MOSKOWITZ MA, BOAS DA: Dynamic imaging of cerebral blood flow using laser speckle. J Cereb Blood Flow Metab 21: 195-201, 2001.

FORSTING M, REITH W, SCHABITZ WR, HEILAND S, VON KUMMER R, HACKE W, SARTOR K: Decompressive craniectomy for cerebral infarction. An experimental study in rats. Stroke 26: 259-264, 1995.

HERZ DA, BAEZ S, SHULMAN K: Pial microcirculation in subarachnoid hemorrhage. Stroke 6: 417-424, 1975.

HUANG X, WEN L: Technical considerations in decompressive craniectomy in the treatment of traumatic brain injury. Int J Med Sci 7: 385-390, 2010.

HUTCHINSON PJ, KOLIAS AG, TIMOFEEV IS, CORTEEN EA, CZOSNYKA M, TIMOTHY J, ANDERSON I, BULTERS DO, BELLI A, EYNON CA, ET AL.: Trial of decompressive craniectomy for traumatic intracranial hypertension. $N$ Engl J Med 375: 1119-1130, 2016.

JAEGER M, SOEHLE M, MEIXENSBERGER J: Effects of decompressive craniectomy on brain tissue oxygen in patients with intracranial hypertension. J Neurol Neurosurg Psychiatry 74: 513-515, 2003.

MITCHELL P, TSENG M, MENDELOW AD: Decompressive craniectomy with lattice duraplasty. Acta Neurochir (Wien) 146: 159-160, 2004.

NORNES H: The role of intracranial pressure in the arrest of hemorrhage in patients with ruptured intracranial aneurysm. J Neurosurg 39: 226-234, 1973.

OTANI N, TAKASATO Y, MASAOKA H, HAYAKAWA T, YOSHINO Y, YATSUSHIGE H, MIYAWAKI H, SUMIYOSHI K, CHIKASHI A, TAKEUCHI S, SUZUKI G: Surgical outcome following decompressive craniectomy for poor-grade aneurysmal subarachnoid hemorrhage in patients with associated massive intracerebral or Sylvian hematomas. Cerebrovasc Dis 26: 612-617, 2008.

PARK KW, METAIS C, DAI HB, COMUNALE ME, SELLKE FW: Microvascular endothelial dysfunction and its mechanism in a rat model of subarachnoid hemorrhage. Anesth Analg 92: 990-996, 2001.

PRUNELL GF, MATHIESEN T, DIEMER NH, SVENDGAARD NA: Experimental subarachnoid hemorrhage: subarachnoid blood volume, mortality rate, neuronal death, cerebral blood flow, and perfusion pressure in three different rat models. Neurosurgery 52: 165-175; discussion 175-176, 2003.

PRUNELL GF, MATHIESEN T, SVENDGAARD NA: A new experimental model in rats for study of the pathophysiology of subarachnoid hemorrhage. Neuroreport 13: 2553-2556, 2002.

PRUNELL GF, MATHIESEN T, SVENDGAARD NA: Experimental subarachnoid hemorrhage: cerebral blood flow and brain metabolism during the acute phase in three different models in the rat. Neurosurgery 54: 426-436; discussion 436-437, 2004. 
ROOKER S, DE VISSCHER G, VAN DEUREN B, BORGERS M, JORENS PG, RENEMAN RS, VAN ROSSEM K, VERLOOY J: Comparison of intracranial pressure measured in the cerebral cortex and the cerebellum of the rat. J Neurosci Methods 119: 83-88, 2002.

SEHBA FA, HOU J, PLUTA RM, ZHANG JH: The importance of early brain injury after subarachnoid hemorrhage. Prog Neurobiol 97: 14-37, 2012.

SEHBA FA, MOSTAFA G, FRIEDRICH V JR, BEDERSON JB: Acute microvascular platelet aggregation after subarachnoid hemorrhage. J Neurosurg 102: 1094-1100, 2005.

SCHUBERT GA, SEIZ M, HEGEWALD AA, MANVILLE J, THOME C: Acute hypoperfusion immediately after subarachnoid hemorrhage: a xenon contrast-enhanced CT study. J Neurotrauma 26: 2225-2231, 2009.

SCHUBERT GA, SCHILLING L, THOME C: Clazosentan, an endothelin receptor antagonist, prevents early hypoperfusion during the acute phase of massive experimental subarachnoid hemorrhage: a laser Doppler flowmetry study in rats. J Neurosurg 109: 1134-1140, 2008.

UOZUMI Y, SAKOWITZ O, ORAKCIOGLU B, SANTOS E, KENTAR M, HAUX D, UNTERBERG A: Decompressive craniectomy in patients with aneurysmal subarachnoid hemorrhage: a single-center matchedpair analysis. Cerebrovasc Dis 37: 109-115, 2014.

VERHAEGEN MJ, TODD MM, WARNER DS, JAMES B, WEEKS JB: The role of electrode size on the incidence of spreading depression and on cortical cerebral blood flow as measured by $\mathrm{H} 2$ clearance. J Cereb Blood Flow Metab 12: 230-237, 1992.

WESTERMAIER T, STETTER C, RASLAN F, VINCE GH, ERNESTUS RI: Brain edema formation correlates with perfusion deficit during the first six hours after experimental subarachnoid hemorrhage in rats. Exp Transl Stroke Med 4: 8, 2012.

YANG XF, WEN L, SHEN F, LI G, LOU R, LIU WG, ZHAN RY: Surgical complications secondary to decompressive craniectomy in patients with a head injury: a series of 108 consecutive cases. Acta Neurochir (Wien) 150: 1241-1247; discussion 1248, 2008. 